\title{
Radiofrequency Ablation of Pancreatic Ductal Adenocarcinoma: An Evolving Comrade?
}

\author{
Panayiotis Hadjicostas, Demetris Christou*, Anastasios Christodoulou \\ Department of General Surgery, Larnaca General Hospital, Larnaca, Cyprus \\ Email: *dr_christou@hotmail.com
}

How to cite this paper: Hadjicostas, P., Christou, D. and Christodoulou, A. (2016) Radiofrequency Ablation of Pancreatic Ductal Adenocarcinoma: An Evolving Comrade? Journal of Cancer Therapy, 7, 1071-1081. http://dx.doi.org/10.4236/jct.2016.713103

Received: May 28, 2016

Accepted: December 25, 2016

Published: December 28, 2016

Copyright $\odot 2016$ by authors and Scientific Research Publishing Inc. This work is licensed under the Creative Commons Attribution-NonCommercial International License (CC BY-NC 4.0).

http://creativecommons.org/licenses/by-nc/4.0/ (c) (i) (8) Open Access

\begin{abstract}
Background: Pancreatic ductal adenocarcinoma (PDAC) presents a challenge for the surgeon due to its aggressiveness and to the stagnation of the management options in cases where complete resection is not feasible. Radiofrequency ablation (RFA) in PDAC is described by a few studies as a promising technique. Methods: We present our 12 years' experience in locally advanced unresectable PDAC with a series of 19 patients. The mean age was 66.8 years. The mean tumour diameter was $8.1 \mathrm{~cm}$. In all patients, RFA was performed during laparotomy using Cooltip@, in some with IOUS monitoring, followed by palliative bypass procedures. Results: The postoperative period was relatively uneventful. A repeat CT showed remarkable changes in the size and morphology of the tumour. We observed significant improvement in pain relief. The mean survival with the RFA was 19.3 months (6 - 30 months). Conclusions: Our series suggest that RFA for locally advanced and unresectable PDAC in carefully selected patients (excluding multifocal disease) presents a promising, effective and safe associate for the surgeon. RFA plays a complimentary role to current standard palliative therapy, which may prolong survival and improve quality of life. Whether the laparoscopic approach or other non-invasive methods are feasible, will be a challenge for the following years.
\end{abstract}

\section{Keywords}

Pancreatic Cancer, Radiofrequency Ablation, Locally Advanced, Surgery

\section{Introduction}

Pancreatic cancer presents a challenge for the clinicians, since the early stages of the disease are relatively symptom-free and therefore usually diagnosed when advanced and non-resectable. This puts pancreatic cancer in the leading 5 most lethal cancers in Europe with more than 104,000 deaths in 2012 (6\% of total) and the 7th most common 
cause of cancer death worldwide, with more than 330,000 deaths in 2012 (4\% of total) [1] [2]. Survival for pancreatic cancer is thus unfortunate, only approximately $20 \%$ surviving one year after diagnosis, with 5-year and 10-year survival rates falling to $3 \%$ and $1 \%$ respectively [3].

Since diagnosed at advanced stage, only the minority of these patients, approximately $20 \%$, will benefit from radical resection [4]. Another $20 \%$ of the patients will have locally advanced but unresectable disease [5] [6] [7]. Despite the advancements in therapeutic means, the outcome remains poor. Several palliative techniques have been employed throughout the years in an attempt to control and regress the growth of the tumour, locally control it, relief its bothersome symptoms, with the ultimate goal of long-term survival. These include palliative chemo-radiation, intraoperative electron beam irradiation/IORT, interstitial or intraluminal brachytherapy [8]-[13].

RFA as a local thermal ablative "debulking" therapy had been used with very good results for the treatment of unresectable hepatic, renal, pulmonary, prostatic, brain and breast cancers [14]. The local destruction of the RFA in these solid tumours deemed an easy and relatively non-demanding approach. When it comes to the "softer" more friable pancreatic tissue, and also due to the close proximity of large vessels and the duodenum that can potentially be lethally damaged, the RFA technique for locally advanced unresectable PDAC becomes more complicated and risky. Therefore, only a few have attempted this palliative technique.

This article presents the experience of a single surgeon over a 12 years period in the treatment of these patients with RFA and our recommendations on the technique.

\section{Patients and Methods}

This article aims to describe our experience with RFA in locally advanced unresectable PDAC from May 2004 till today. All procedures were performed by the same surgeon. During these 12 years we treated 19 patients with intraoperative RFA using Cooltip@. The male to female ratio was 2.8:1 (14 males and 5 females), aged $45-80$ years (mean = 66.8). They presented to our departments with various symptoms including anorexia, weight loss, fatigue, pruritus, back pain and in most of the cases painless obstructive jaundice. During workup with abdominal US scan and three-phases CT scan with intravenous contrast revealed suspicious lesion on the pancreas. The size $(5-15 \mathrm{~cm}$; mean $=8.1 \mathrm{~cm}$ ) and location of the lesion (head of pancreas:body/tail 17:2) varied. The criteria used to define these lesions as locally advanced unresectable tumours of the pancreas included the absence of distant metastases but the encasement or adherence of adjacent large vessels such as the portal vein and the superior mesenteric vein and artery. In some patients the histologic diagnosis of PDAC was obtained by percutaneous CT guided biopsy, others by biopsy obtained during ERCP and others by endoscopic US and biopsy.

The patients were all informed about the incapability of complete surgical resection and offered the option of palliative surgery and intraoperative RFA. All patients underwent an explorative laparotomy, Kocher mobilisation of the duodenum and the 
head of the pancreas and RFA was performed under direct vision of the tumour. We used the latest Cooltip@ RFAblation (Radionics) system. The cooltip electrode was a 17 -gauge, $15 \mathrm{~cm}$ with $3 \mathrm{~cm}$ length for rapid tumour destruction (Figure $1 \&$ Figure 2). Simultaneous infusion/perfusion with cold normal saline of the areas surrounding tissues was done during the ablation to further avoid burn damage. The duodenum was in direct vision, however, the large vessels were not directly seen during the initial cases, but in the last 8 patients we performed intraoperative US (IOUS) in the attempt to definitely avoid ablating anywhere near these vessels (Figure 3 ), a technique that is advisable. The RFA in all these patients was done for duration of $2-5$ minutes and in $2-3$ different sites in the tumour (overlapping technique) at a temperature of $60-70$ degrees Celsius.

In all the patients the RFA was followed by palliative bypass procedures (loop or Roux-en-Y cholecystojejunostomy/choledochojejunostomy and Braun-type side-to-side enteroenterotomy and/or gastrojejunostomy, according to the individual case) (Figure 4).

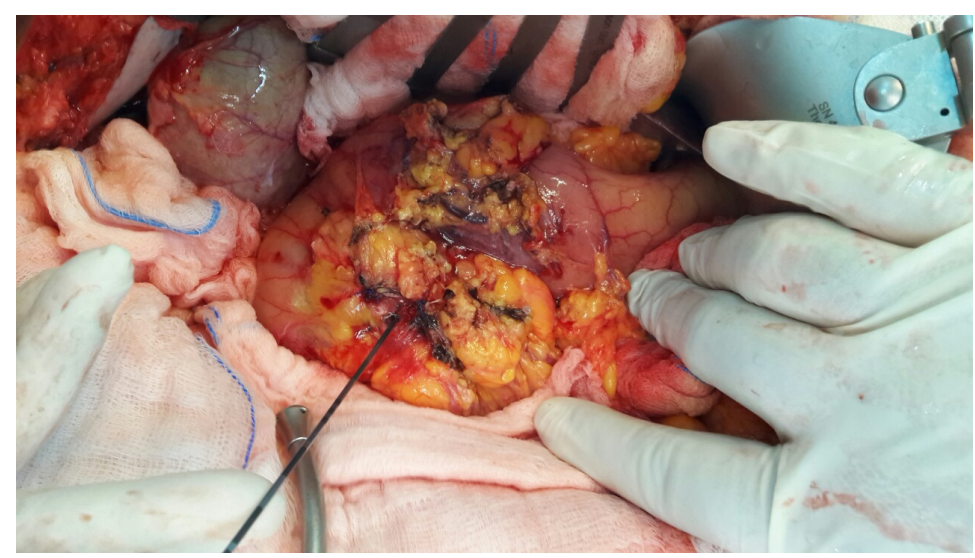

Figure 1. RFA of tumor of the head of pancreas.

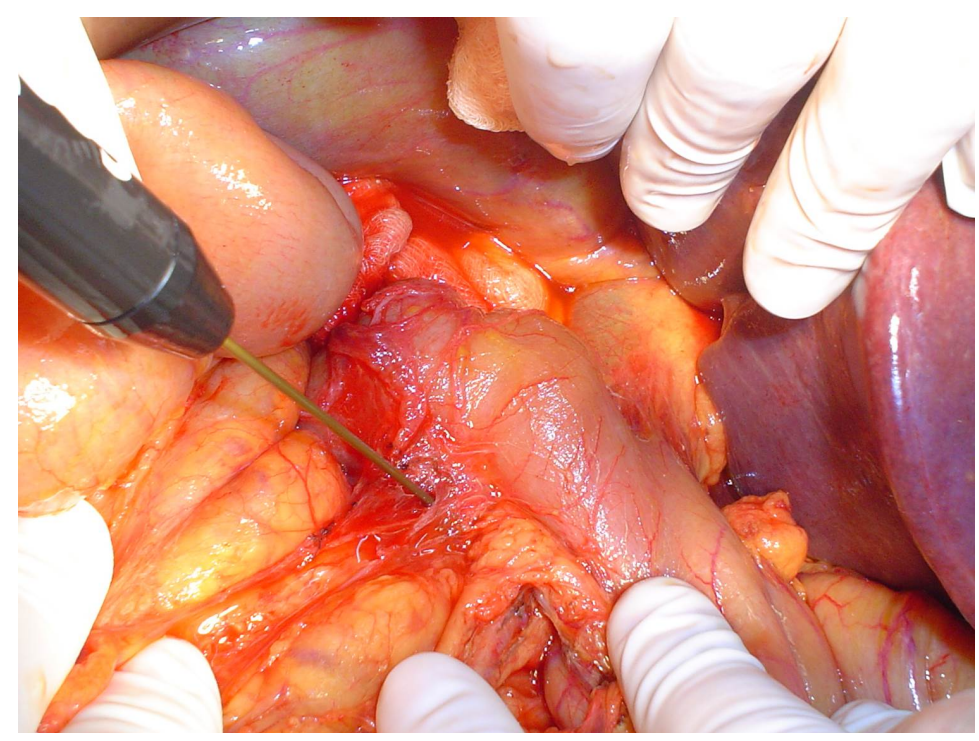

Figure 2. Kocher mobilization and RFA of tumor of the head of pancreas. 


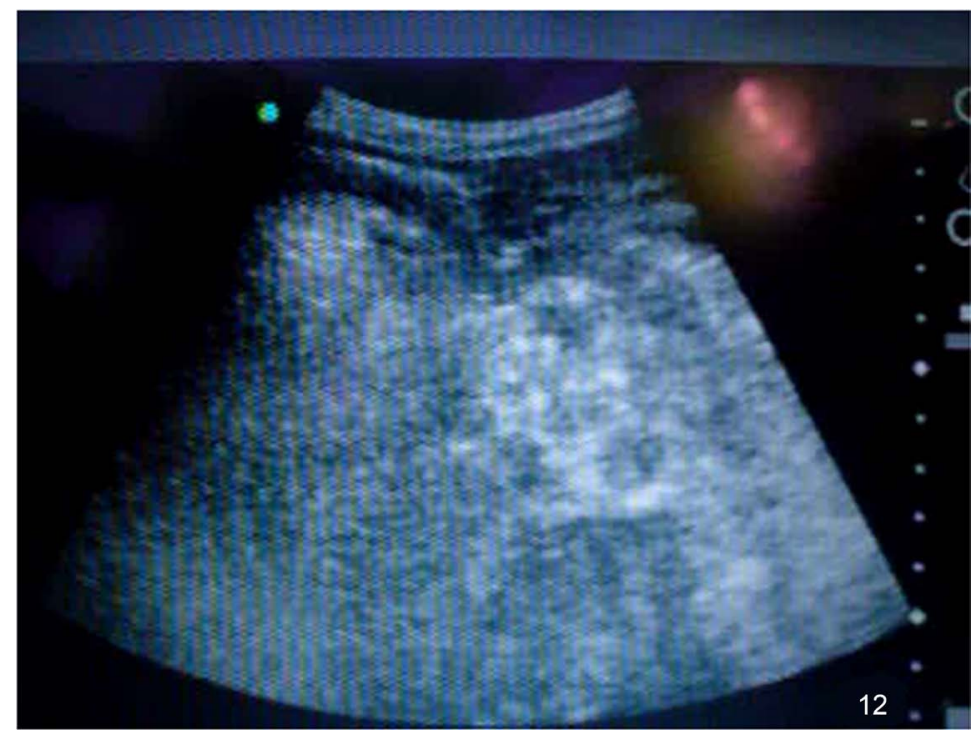

Figure 3. The use of IOUS during RFA.

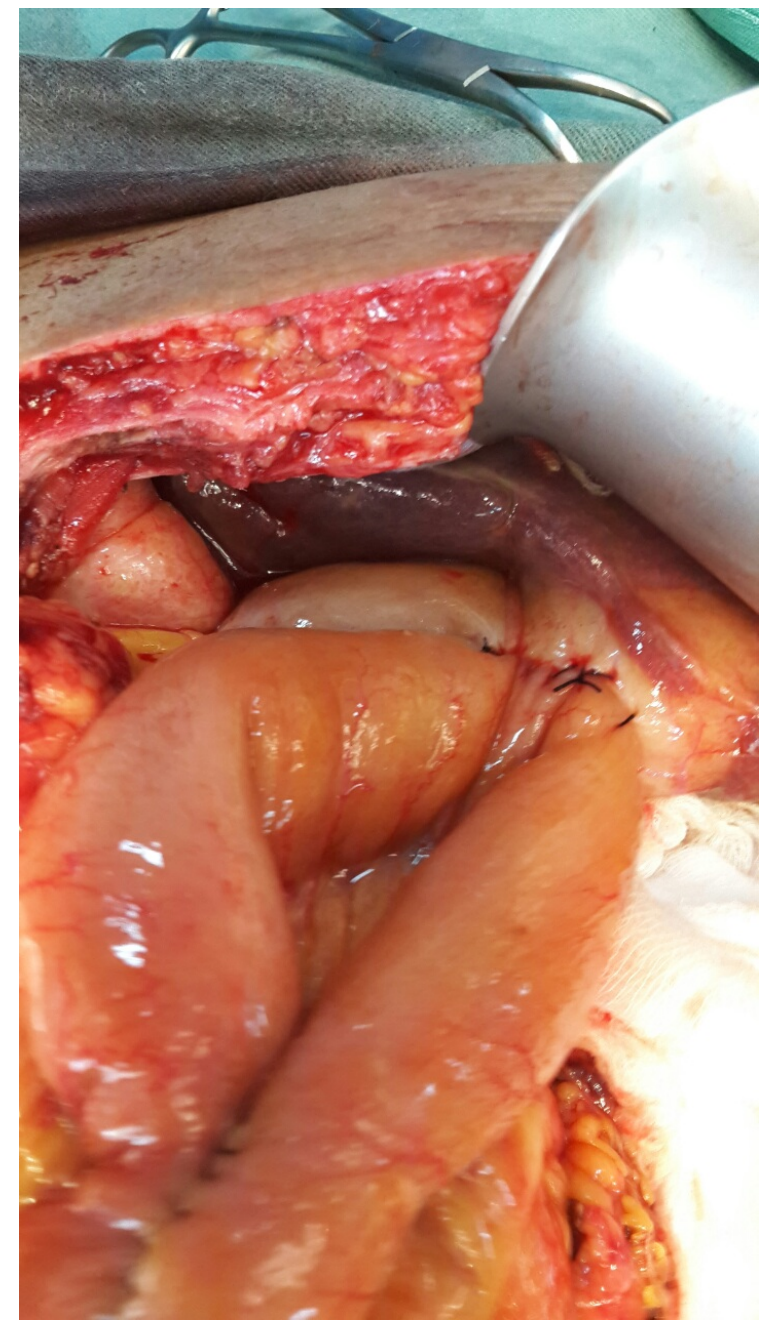

Figure 4. Palliative cholecystojejunostomy bypass procedure. 
These palliative bypass procedures were done for the obvious two reasons of biliary or duodenal obstruction but also as a precaution measure in case of duodenal thermal damage because of the RFA. A drainage tube was placed by the ablated area. The postoperative serum and peritoneal fluid amylase was measured for 5 days. Furthermore, the patients were administered prophylactically subcutaneous octreotide (Sandostatin) for 3 - 5 days.

\section{Results}

The technique for RFA was time and cost efficient and deemed no procedural difficulties. All of our patients had an uneventful and uncomplicated postoperative period. None of the patients was complicated with pancreatitis; however, 3 of them had asymptomatic hyperamylasaemia which resolved spontaneously. A repeat abdominal CT scan with intravenous contrast was performed in all patients one month and six months after the operation, which showed remarkable changes in the morphology of the tumour in almost of the patients (in one month), and also in the size of the tumour (in 6 months) (Figure 5 \& Figure 6). The intention to control and regress the growth of the tumour and locally control extending was achieved. In one patient the tumour was undetectable in a repeat CT scan 6 months later. We also observed significant improvement in pain relief especially in the two cases where the tumour was found at the body of pancreas. The ultimate goal of longer-term survival was also attained. The mean survival of our patients post the RFA was 19.3 months (6 - 30 months).

\section{Discussion}

Pancreatic cancer is one of the most lethal neoplasms acquired by mankind. Due to its natural history and aggressiveness, it has a dismal prognosis at diagnosis. About $40 \%$ of pancreatic cancers are unresectable at diagnosis, condemning the patient to certain

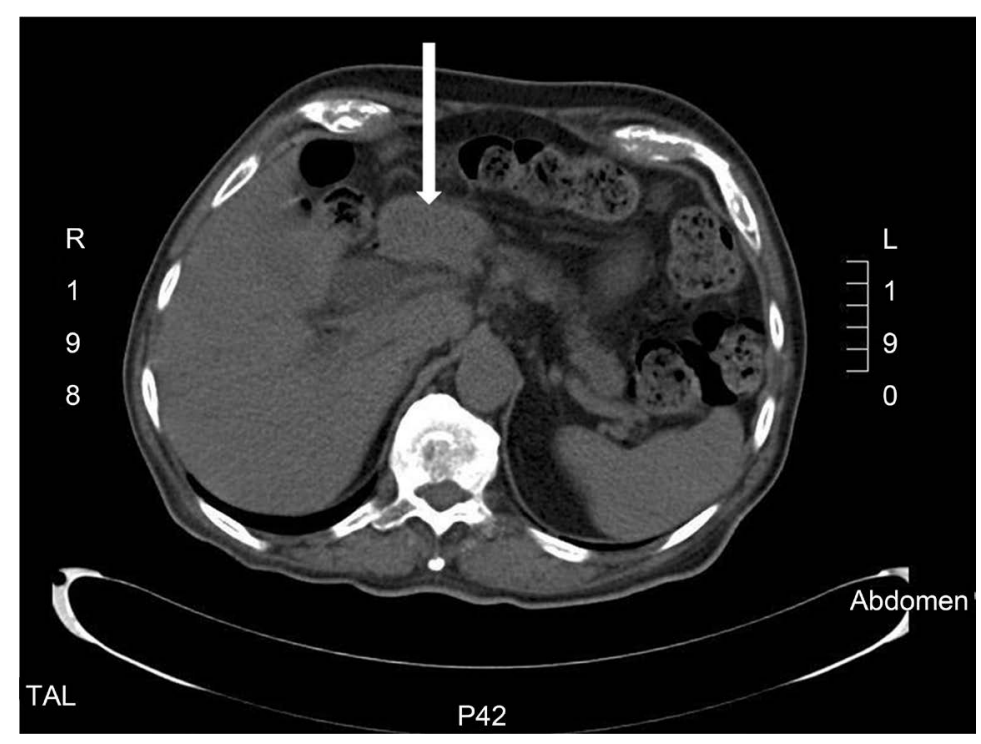

Figure 5. Tumour of the head of the pancreas before RFA. 


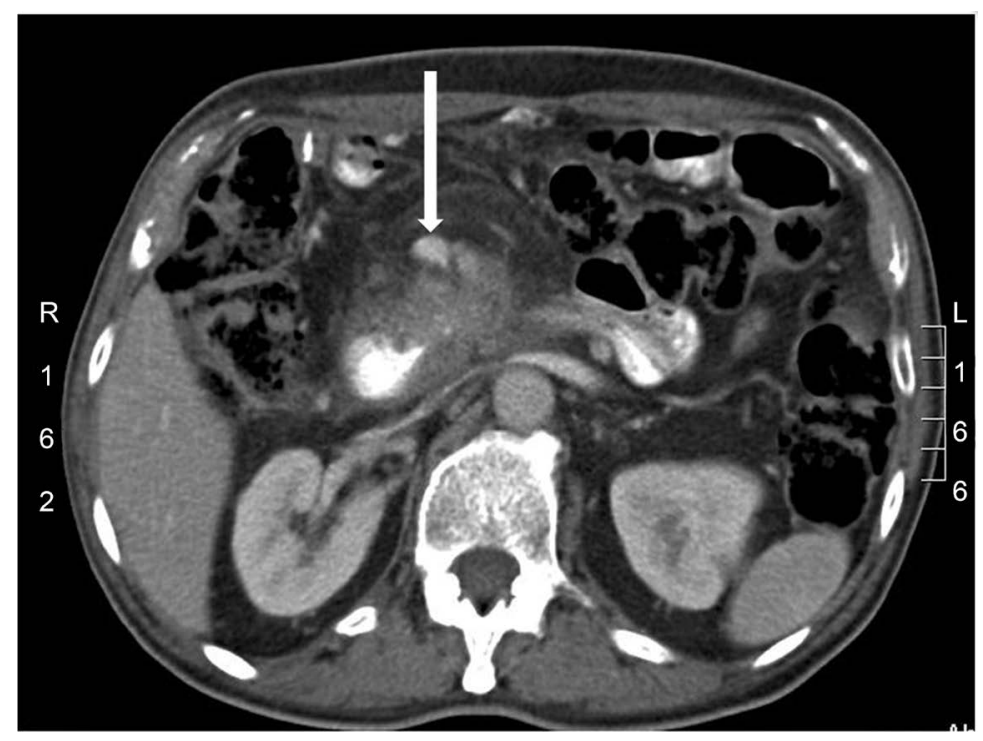

Figure 6. Changes in the morphology of the tumour one month after the RFA.

death within only a few months [15]. While oncologists still have no magical answers, the surgeons may offer 'solutions' with a new tool in their toolbox, RFA.

RFA as a novel local therapy has shown encouraging results in terms of safety and feasibility and has been shown to improve survival, reduce morbidity and improve Quality of Life (QoL) in these patients were diagnosis of pancreatic cancer was late. This technique therefore can be used for PDAC that is locally advanced (stage III) [16]-[21], even though it has also been shown to have positive results in selected patients with systemic involvement (stage IV) [22] [23] [24] but also importantly in patients who cannot tolerate a major pancreatic resection. Patient selection is very important before applying RFA and topics that need to be considered include patient comorbidities, QoL expected after the RFA, patient preferences and response to neo-adjuvant medical oncological treatment if any. Tumour size is not a contraindication [15], however, these tumours require more extensive ablation (Figure 7 \& Figure 8).

RFA as a local thermal technique aims to ultimately destroy the tumour at a cellular level inducing coagulative necrosis and protein denaturation, acting as a "salvage" local cytoreductive therapy. RFA can be done during laparotomy (our preferred method), percutaneously ( $76 \%$ of our liver RFA series) or more recently endoscopically. The technique proposed by us is with the use of Cooltip@ RFAblation (Radionics) system, 17 -gauge, $15 \mathrm{~cm}$ with $3 \mathrm{~cm}$ length electrode for rapid tumour destruction and simultaneous infusion/perfusion with cold normal saline of the surrounding tissues during the ablation in order to avoid burn damage, during laparotomy. The duration of the ablation ranges from 2 - 5 minutes in 2 - 3 different sites in the tumour at a temperature of 60 - 70 degrees Celsius. We advise an IOUS during the procedure in order to avoid ablating $5-10 \mathrm{~mm}$ near the portomesenteric vessels and the duodenum. Some authors also advice cooling the duodenum during the procedure with cold normal saline through a nasogastric tube in order to avoid thermal damage, a procedure that we did 


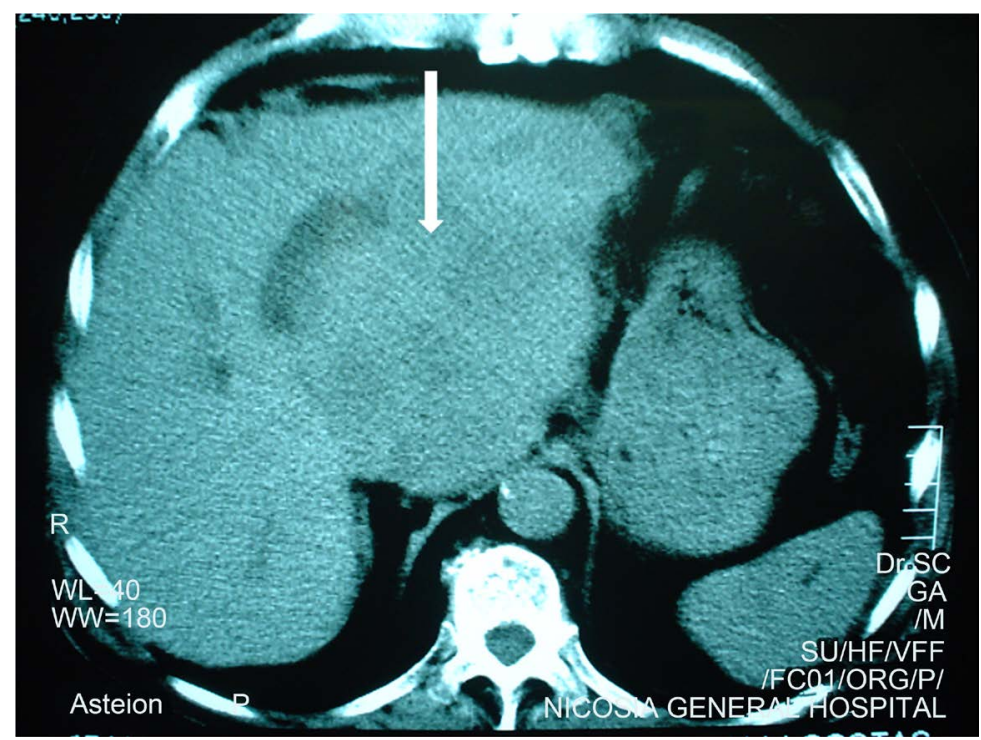

Figure 7. A huge pancreatic tumour before RFA.

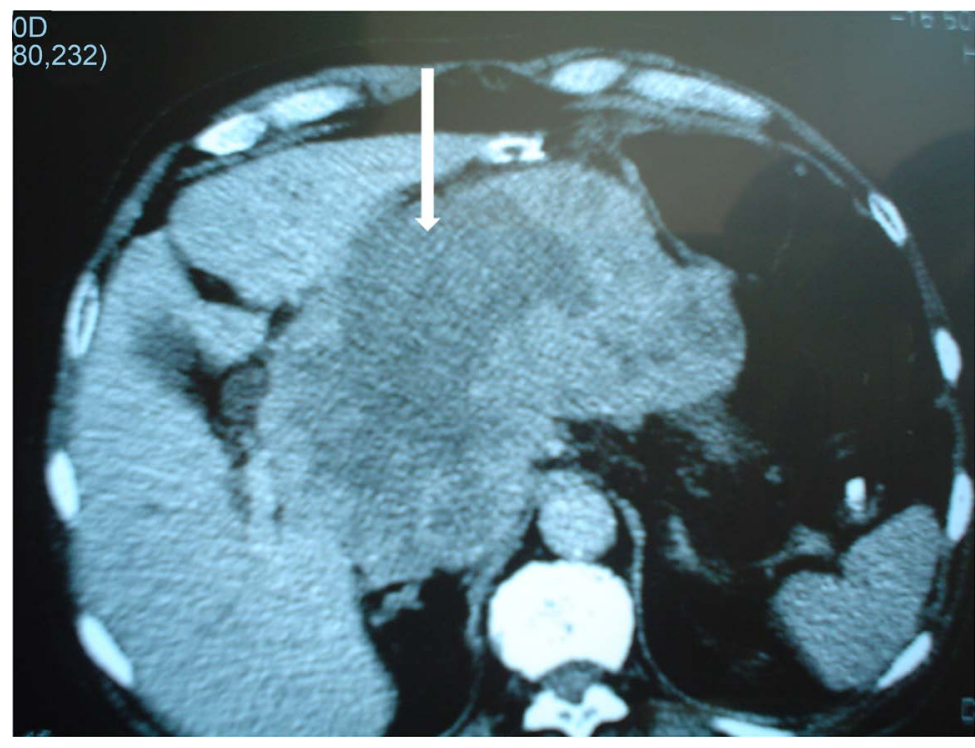

Figure 8. Changes in the morphology of the tumour one month post RFA.

not follow since we performed extensive and direct simultaneous cooling of the surrounding ablated area during the procedure with cold normal saline. Apart from thermal damage and injury to the duodenum and the portomesenteric vessels, other complications reported include gastrointestinal haemorrhages, minor local bleeding, acute pancreatitis (mild or severe), asymptomatic hyperamylaseamia and pancreatic and biliary fistulas. Since the RFA approach in these patients has a palliative intention, we completing the operation with palliative biliary and enteric bypass procedures such as cholecystojejunostomy and gastrojejunostomy are considered obligatory by us. Bearing this in mind then, the internal cooling of the common bile duct, as suggested by some authors is futile. We further suggest the use of subcutaneous octreotide (Sandostatin) 
prophylactically and also the monitoring of the serum and peritoneal amylase level postoperatively.

RFA has also been shown to act as an 'endogenous vaccine' against the neoplastic effects. This interesting observation of the RFA's strong positive anti-tumoral effect on the immune system has been described extensively by Chu and Dupuy [25]. Several authors proved the direct effect that RFA has on adjacent tissues causing an alteration of metabolic endocellular processes which makes them more sensitive to adjuvant cytolytic therapies such as chemo-radiotherapy. Furthermore, several studies demonstrated how RFA can boost the systemic immune response against the tumour by releasing proinflammatory cytokines [26] [27] [28], lymphocytes (T-, B-, and NK-types) [29] [30] [31] [32], and antibodies [33] that are responsible for acquired anti-tumoral antigen-specific immunity [34] [35] with ultimate goal the improved survival in the patients.

The use of RFA in locally advanced PDAC, even though not proven by large randomised controlled studies, has been shown to have very encouraging oncological outcomes. Spiliotis et al. compared RFA only with systemic treatment only in stage III PDAC and showed excellent results with RFA only with an increase in mean survival to the amazing of 30 months compared to only 13 months in patients receiving only systemic treatment $(\mathrm{p}=0.0048)$ [18]. Furthermore, a previous article by the author $\mathrm{P}$. Hadjicostas et al. observed a significant effect in pain relief in these patients, which played an important role in the palliative approach of the procedure [19]. Also, Giardino et al. suggested the so called "triple approach strategy" where RFA is also combined with systemic chemo-radiotherapy and intra-arterial chemotherapy, with even better results and overall survival reaching 34 months [36].

In the current study we incorporated the use of RFA during laparotomy combined with palliative bilioenteric and enteroenteric bypass procedures which yielded promising results in terms of tumour reduction, pain relief and overall survival. We suggest the use of the Cooltip $\odot$ RFAblation (Radionics) system intraoperatively (under direct vision) with the use of IOUS and local cooling with cold normal saline of the surrounding tissues in order to minimise the risk of direct thermal damage to the portomesenteric vessels, the extrahepatic biliary system or the duodenum.

\section{Conclusion}

In the hostile situation of pancreatic cancer that is unfortunately locally advanced and therefore unresectable, there is growing evidence that RFA can be a comrade for the surgeon. Our series suggest that the use of RFA for locally advanced and unresectable PDAC in carefully selected patients (excluding multifocal disease) presents a promising, effective and safe associate for the surgeon. Given the fact that is applicable to these high risk patients with relatively low cost, morbidity and time, its proven anti-tumoral effect, we believe that RFA can be used with confidence as part of the multimodal treatment of locally advanced PDAC. RFA can play a complimentary role to current standard palliative therapy, which may prolong survival and improve quality of life. 
Whether the laparoscopic approach for ablation or other non-invasive ablative methods are feasible, will be a challenge for the following years.

\section{References}

[1] Ferlay, J., Soerjomataram, I., Ervik, M., Dikshit, R., Eser, S., Mathers, C., Rebelo, M., Parkin D.M., Forman, D. and Bray, F. (2013) GLOBOCAN 2012 v1.0, Cancer Incidence and Mortality Worldwide: IARC Cancer Base No. 11. International Agency for Research on Cancer, yon, France. http://globocan.iarc.fr

[2] Ferlay, J., Steliarova-Foucher, E., Lortet-Tieulent, J., et al. (2013) Cancer Incidence and Mortality Patterns in Europe: Estimates for 40 Countries in 2012. European Journal of Cancer, 49, 1374-1403. https://doi.org/10.1016/j.ejca.2012.12.027

[3] (2014) Data Were Provided to Cancer Research UK by London School of Hygiene and Tropical Medicine on Request.

[4] Wagner, M., Friess, H. and Buchler, W.M. (2015) Conservative versus Radical Resections of the Pancreas, Pancreatic Cancer: Molecular and Clinical Advances. Blackwell Science Ltd., Oxford.

[5] Smeenk, H.G., Tran, T.C.K., Erdmann, J., van Eijck, C.H.J. and Jeekel, J. (2005) Survival after Surgical Management of Pancreatic Adenocarcinoma: Does Curative and Radical Surgery Truly Exist? Langenbeck's Archives of Surgery, 390, 94-103. https://doi.org/10.1007/s00423-004-0476-9

[6] Kleeff, J., Reiser, C., Hinz, U., et al. (2007) Surgery for Recurrent Pancreatic Ductal Adenocarcinoma. Annals of Surgery, 245, 566-572.

[7] Morganti, A.G., Massaccesi, M., La Torre, G., et al. (2010) A Systematic Review of Resectability and Survival after Concurrent Chemoradiation in Primarily Unresectable Pancreatic Cancer. Annals of Surgical Oncology, 17, 194-205.

https://doi.org/10.1245/s10434-009-0762-4

[8] Shipley, W.U., Wood, W.C., Tepper, J.E., Warshaw, A.L., Orlow, E.L., Kaufman, S.D., et al. (1984) Intraoperative Electron Beam Irradiation for Patients with Unresectable Pancreatic Carcinoma. Annals of Surgery, 200, 289-296.

https://doi.org/10.1097/00000658-198409000-00006

[9] Mohiuddin, M., Rosato, F., Barbot, D., Schuricht, A., Biermann, W. and Cantor, R. (1992) Long Term Results of Combined Modality Treatment with I-125 Implantation for Carcinoma of the Pancreas. International Journal of Radiation Oncology ${ }^{*}$ Biology ${ }^{*}$ Physics, 23, 305-311. https://doi.org/10.1016/0360-3016(92)90746-5

[10] Bodner, R.W. and Hilaris, S.B. (1997) Brachytherapy and Pancreatic Cancer. Seminars in Surgical Oncology, 13, 204-207. https://doi.org/10.1002/(SICI)1098-2388(199705/06)13:3<204::AID-SSU8>3.0.CO;2-B

[11] Nori, D., Merimsky, O., Osian, A., Heffeman, M., Cortes, E. and Turner, J.W. (1996) Palladium-103: A New Radioactive Source in the Treatment of Unresectable Carcinoma of the Pancreas: A Phase I-II Study. Journal of Surgical Oncology, 61, 300-305. https://doi.org/10.1002/(SICI)1096-9098(199604)61:4<300::AID-JSO14>3.0.CO;2-9

[12] Wanebo, H.J., Glicksman, A.S., Vezerides, M.P., Clark, J., Tibbetts, L., Koness, R.J., et al. (2000) Preoperative Chemotherapy, Radiotherapy and Surgical Resection of Locally Advanced Pancreatic Cancer. Archives of Surgery, 135, 81-87. https://doi.org/10.1001/archsurg.135.1.81

[13] Mutignani, M., Shah, K.S., Morganti, A.G., Perri, V., Macchia, G. and Costamagna, G. (2002) Treatment of Unresectable Pancreatic Carcinoma by Intraluminal Brachytherapy in 
the Duct of Wirsung. Endoscopy, 34, 555-559. https://doi.org/10.1055/s-2002-33214

[14] Mirza, A.N., Fornage, B.D., Sneige, N., Kuerer, H.M., Newman, L.A., Ames, F.C., et al. (2001) Radiofrequency Ablation of Solid Tumours. The Cancer Journal, 7, 95-102.

[15] Salvatore, P., Roberto, S., Marco, R., Roberto, G., Isabella, F., Alessandro, G., Valentina, A. and Claudio, B. (2016) Local Ablative Strategies for Ductal Pancreatic Cancer (Radiofrequency Ablation, Irreversible Electroporation): A Review. Gastroenterology Research and Practice, 2016, Article ID: 4508376. https://doi.org/10.1155/2016/4508376

[16] Keane, M.G., Bramis, K., Pereira, S.P. and Fusai, G.K. (2014) Systematic Review of Novel Ablative Methods in Locally Advanced Pancreatic Cancer. World Journal of Gastroenterology, 20, 2267-2278. https://doi.org/10.3748/wjg.v20.i9.2267

[17] Girelli, R., Frigerio, I., Giardino, A., et al. (2013) Results of 100 Pancreatic Radiofrequency Ablations in the Context of a Multimodal Strategy for Stage III Ductal Adenocarcinoma. Langenbeck's Archives of Surgery, 398, 63-69. https://doi.org/10.1007/s00423-012-1011-z

[18] Spiliotis, J.D., Datsis, A.C., Michalopoulos, N.V., et al. (2007) Radiofrequency Ablation Combined with Palliative Surgery May Prolong Survival of Patients with Advanced Cancer of the Pancreas. Langenbeck's Archives of Surgery, 392, 55-60. https://doi.org/10.1007/s00423-006-0098-5

[19] Hadjicostas, P., Malakounides, N., Varianos, C., Kitiris, E., Lerni, F. and Symeonides, P. (2006) Radiofrequency Ablation in Pancreatic Cancer. HPB, 8, 61-64. https://doi.org/10.1080/13651820500466673

[20] Figueroa-Barojas, P., Bakhru, M.R., Habib, N.A., et al. (2013) Safety and Efficacy of Radiofrequency Ablation in the Management of Unresectable Bile Duct and Pancreatic Cancer: A Novel Palliation Technique. Journal of Oncology, 2013, Article ID: 910897.

[21] Varshney, S., Sewkani, A., Sharma, S., et al. (2006) Radiofrequency Ablation of Unresectable Pancreatic Carcinoma: Feasibility, Efficacy and Safety. Journal of the Pancreas, 7, 74-78.

[22] Wu, Y., Tang, Z., Fang, H., et al. (2006) High Operative Risk of Cool Tip Radiofrequency Ablation for Unresectable Pancreatic Head Cancer 1. Journal of Surgical Oncology, 94, 392395. https://doi.org/10.1002/jso.20580

[23] Matsui, Y., Nakagawa, A., Kamiyama, Y., Yamamoto, K., Kubo, N. and Nakase, Y. (2000) Selective Thermocoagulation of Unresectable Pancreatic Cancers by Using Radiofrequency Capacitive Heating. Pancreas, 20, 14-20. https://doi.org/10.1097/00006676-200001000-00002

[24] Date, R.S. and Siriwardena, A.K. (2005) Radiofrequency Ablation of the Pancreas. II: Intra-Operative Ablation of Non-Resectable Pancreatic Cancer. A Description of Technique and Initial Outcome. Journal of the Pancreas, 6, 588-592.

[25] Chu, K.F. and Dupuy, D.E. (2014) Thermal Ablation of Tumours: Biological Mechanisms and Advances in Therapy. Nature Reviews Cancer, 14, 199-208. https://doi.org/10.1038/nrc3672

[26] Ali, M.Y., Grimm, C.F., Ritter, M., et al. (2005) Activation of Dendritic Cells by Local Ablation of Hepatocellular Carcinoma. Journal of Hepatology, 43, 817-822. https://doi.org/10.1016/j.jhep.2005.04.016

[27] Evrard, S., Menetrier-Caux, C., Biota, C., et al. (2007) Cytokines Pattern after Surgical Radiofrequency Ablation of Liver Colorectal Metastases. Gastroentérologie Clinique et Biologique, 31, 141-145. https://doi.org/10.1016/S0399-8320(07)89344-4

[28] Fietta, A.M., Morosini, M., Passadore, I., et al. (2009) Systemic Inflammatory Response and Downmodulation of Peripheral CD25+Foxp3+ T-Regulatory Cells in Patients Undergoing 
Radiofrequency Thermal Ablation for Lung Cancer. Human Immunology, 70, 477-486. https://doi.org/10.1016/j.humimm.2009.03.012

[29] Jansen, M.C., van Wanrooy, S., van Hillegersberg, R., et al. (2008) Assessment of Systemic Inflammatory Response (SIR) in Patients Undergoing Radiofrequency Ablation or Partial Liver Resection for Liver Tumours. European Journal of Surgical Oncology, 34, 662-667. https://doi.org/10.1016/j.ejso.2007.06.009

[30] Zerbini, A., Pilli, M., Laccabue, D., et al. (2010) Radiofrequency Thermal Ablation for Hepatocellular Carcinoma Stimulates Autologous NK-Cell Response. Gastroenterology, 138, 1931-1942. https://doi.org/10.1053/j.gastro.2009.12.051

[31] Hansler, J., Wissniowski, T.T., Schuppan, D., et al. (2006) Activation and Dramatically Increased Cytolytic Activity of Tumour Specific T Lymphocytes after Radio-Frequency Ablation in Patients with Hepatocellular Carcinoma and Colorectal Liver Metastases. World Journal of Gastroenterology, 12, 3716-3721.

[32] Napoletano, C., Taurino, F., Biffoni, M., et al. (2008) RFA Strongly Modulates the Immune System and Anti-Tumour Immune Responses in Metastatic Liver Patients. International Journal of Oncology, 32, 481-490. https://doi.org/10.3892/ijo.32.2.481

[33] Widenmeyer, M., Shebzukhov, Y., Haen, S.P., et al. (2011) Analysis of Tumour Antigen-Specific T Cells and Antibodies in Cancer Patients Treated with Radiofrequency Ablation. International Journal of Cancer, 128, 2653-2662. https://doi.org/10.1002/ijc.25601

[34] Dromi, S.A., Walsh, M.P., Herby, S., et al. (2009) Radiofrequency Ablation Induces Antigen-Presenting Cell Infiltration and Amplification of Weak Tumour-Induced Immunity. Radiology, 251, 58-66. https://doi.org/10.1148/radiol.2511072175

[35] Rovere-Querini, P. and Manfredi, A.A. (2004) Tumour Destruction and in Situ Delivery of Antigen Presenting Cells Promote Anti-Neoplastic Immune Responses: Implications for the Immunotherapy of Pancreatic cancer. Journal of the Pancreas, 5, 308-314.

[36] Giardino, A., Girelli, R., Frigerio, I., et al. (2013) Triple Approach Strategy for Patients with Locally Advanced Pancreatic Carcinoma. $H P B, 15,623-627$. https://doi.org/10.1111/hpb.12027

Submit or recommend next manuscript to SCIRP and we will provide best service for you:

Accepting pre-submission inquiries through Email, Facebook, LinkedIn, Twitter, etc.

A wide selection of journals (inclusive of 9 subjects, more than 200 journals)

Providing 24-hour high-quality service

User-friendly online submission system

Fair and swift peer-review system

Efficient typesetting and proofreading procedure

Display of the result of downloads and visits, as well as the number of cited articles

Maximum dissemination of your research work

Submit your manuscript at: http://papersubmission.scirp.org/

Or contact jet@scirp.org 